\title{
Role of Argyrophilic Nucleolar Organiser Region Staining in Effusions for Detection of Malignancy - Diagnostic Test Evaluation
}

\author{
Authors

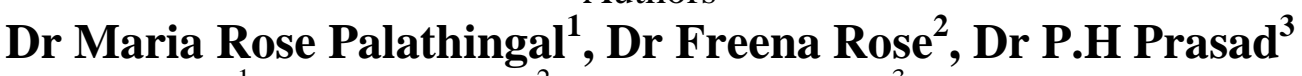 \\ ${ }^{1}$ Senior Resident, ${ }^{2}$ Assistant Professor, ${ }^{3}$ Professor \\ Dept of Pathology, Government Medical College, Thrissur, Kerala \\ Corresponding Author
}

Dr Freena Rose

Assistant Professor, Dept of Pathology, Government Medical College, Thrissur, Kerala, Pin 680596

Phone No: 9446551832, 0487 2204832,Email: freenarose@yahoo.com

\begin{abstract}
The frequency of AgNORs within the nuclei is higher in malignant cells than in normal, reactive or benign neoplastic cells. 80 serous effusions received in the Cytology Lab during the study period, which could be proved as benign or malignant by biopsy were included \& AgNOR study was done. Statistically significant difference was noted in AgNOR size, count, dispersion \& mean AgNOR value between benign \& malignant effusions. AgNOR study appears to be clinically useful as an additional diagnostic tool in serous effusion when the cytologic diagnosis is difficult.
\end{abstract}

Keywords: AgNOR Staining, benign and malignant effusions.

\section{Introduction}

Nucleolar organizer regions (NORs) identified by argyrophilia technique, represent loops of DNA encoding for ribosomal RNA and are related to cell ploidy, proliferative activity or rate of transcription. NORs are important in protein synthesis and the formation of the nucleolus ${ }^{[1]}$. The frequency of AgNORs within the nuclei is higher in malignant cells than in normal, reactive or benign neoplastic cells $^{[2]}$. In a rapidly proliferating cell, the chromosomal and AgNOR distribution remains disorganized with the resultant formation of multiple, small and dispersed nucleoli ${ }^{[3]}$.

A variety of conditions ranging from inflammatory to neoplastic, cause effusions. Malignant tumors will cause effusion by direct involvement of serous membranes by tumor invasion or by secondary inflammatory reaction ${ }^{[4]}$. Detection of malignant cells in effusion is important for clinical staging of tumor and deciding the line of treatment.

An accurate identification of tumor cells in pleural and peritoneal fluids is often difficult. Sensitivity of conventional cytology for the identification of malignant cells varies from 50-78\%. ${ }^{[5]}$. Histochemical stains, electron microscopy and immunecytochemical studies can aid cytological evaluation of effusions for getting a definitive diagnosis, but such methods are time consuming and costly, and some antigens suitable for this purpose are expressed by normal as well as reactively proliferated mesothelial cells ${ }^{[6]}$. A relatively simple and effective technique used for differentiating reactive and malignant effusions is the silver staining of the nucleolar organizer region (AgNOR). 
Visualization of NORs in mammalian chromosomes by silver staining was done by Good pasture and Bloom in $1975^{[7]}$. Crocker and Nar introduced silver staining of NORs into pathology as a new diagnostic method for distinguishing benign and malignant lesions in $1987^{[8]}$. Following this, a variety of pathologic conditions were analyzed with this technique, The first application of AgNOR staining on human effusion for differentiating malignant, reactive and normal mesothelial cells was performed by Derenzini et al in $1989^{[9]}$.

According to the study of Wolanski et al in 1998, AgNOR area was of greater diagnostic significance than AgNOR count and above a threshold of 0.6677 $\mathrm{m} 2$ area per cell, most cases were malignant ${ }^{[10]}$. In 2002, Torabi-Nezhad et al, demonstrated that in the three groups (normal, benign reactive and malignant) the normal mesothelial cells have the least AgNOR counts with uniformly sized, small black dots ${ }^{[11]}$. Ibnerasa et al (2005) reported that AgNOR proliferative Index (pAgNOR-percentage of tumour cells with more than 5 AgNORs per nucleus) in most of the malignant effusions was above $90 \%{ }^{\text {[12] }}$

Karki S et al (2012) found that AgNOR count can be used as an important additional diagnostic tool for use in ascitic and pleural fluid samples when routine cytological diagnosis is difficult ${ }^{[4]}$ This was later supported by Mohamed Fagere in $2016^{[13]}$

\section{Materials and Methods}

All malignant or reactive - pleural, peritoneal or pericardial effusions received in the Cytology Lab, Department of Pathology, Government Medical College, Thrissur, during the period - 01/01/2014 to $30 / 06 / 2015$ which could be proved as benign or malignant by biopsy were included. The effusions were centrifuged at a speed of $2000 \mathrm{rpm}$ for 5 minutes. Smear were prepared from sediment for AgNOR staining and quickly immersed in $95 \%$ ethanol before drying.

AgNOR staining solution was prepared by dissolving $2 \mathrm{~g}$ of gelatin in $1 \%$ aqueous formic acid to make $100 \mathrm{ml}$ solution at a concentration of $2 \%$ (solution A). Fifty percent aqueous silver nitrate solution was prepared by dissolving $5 \mathrm{~g}$ of silver nitrate in triple distilled water to make $10 \mathrm{ml}$ solution (solution B). Working solution was prepared by mixing solution $\mathrm{A}$ and $\mathrm{B}$ in a proportion of 1: 2 volumes and poured over the smears immediately after preparation and left for 60 minutes at room temperature. The silver colloid formed was washed off with triple distilled water and the smears were counterstained with neutral red $1.0 \%$. Smears were washed with triple distilled water and dehydrated through ascending grades of alcohol, cleared with xylene and mounted in DPX. When extra unstained smear were not available, silver staining was done on Pap or Giemsa stained smears after distaining.

AgNORs were counted using $\times 100$ oil immersion objective as black dots in the nuclei of all cells. The pattern of AgNOR dispersion and their shape was compared in reactive and malignant cases. The mean number of AgNORs per nuclei was calculated for each sample.

The size variation and distribution of AgNORs were performed by the following criteria used by Ahsan et al ${ }^{[14]}$.

Distribution of AgNORs in the nuclei was graded as

$0=$ limited to the nucleoli

$1+=$ occasional dispersion outside nucleoli

$2+=$ Moderate dispersion outside nucleoli

$3+=$ widely dispersed throughout the nucleus

Size variation of AgNORs was graded as

$0=$ more or less uniform in size

$1+=$ two different sizes

$2+=$ more than two different sizes

$3+=$ all grades and sizes including too minute to be counted

Data was collected and entered in Microsoft Excel 2007 sheet. Statistical analysis was done by ChiSquare tests and Fisher's Exact Test. Cross tabulations were done using SPSS software version 16.

\section{Observations and Results}

Total 80 cases of effusions were observed. The age of the patients ranged from 21-88 year with frequent age group being $41-60$ years $(50 \%)$. The mean age was 60.32. 15 cases $(18.75 \%)$ were males and 
65cases $(81.25 \%)$ were females. Among the 80 samples, 48 were peritoneal effusions and 32 were pleural effusions.

Majority (86\%) were reactive effusions. Only $14 \%$ were malignant effusions

Among the 11 malignant effusions, 10 cases were peritoneal effusions and the remaining was pleural effusion

Table -1 Frequency of malignant effusions

\begin{tabular}{|l|c|c|}
\hline \multicolumn{1}{|c|}{ Site } & Frequency & Percent \\
\hline Peritoneal & 10 & $91 \%$ \\
\hline Pleural & 1 & $9 \%$ \\
\hline Total & 11 & $100 \%$ \\
\hline
\end{tabular}

The primary site was ovary in 9cases of malignant peritoneal effusions and stomach in 1case. In malignant pleural effusion, primary site of carcinoma was lung.

AgNOR Size in Reactive and Malignant, Peritoneal and Pleural Effusions

In reactive, non-malignant effusions AgNORs were homogenous in size and graded as 0 (uniform size) and $1+$ (two different sizes). Whereas in malignant effusions AgNORs were heterogenous in size and graded as $2+$ (more than two different sizes) and $3+$ (various grades and sizes).

Table -2 AgNOR size in reactive and malignant effusions

\begin{tabular}{|l|c|c|c|c|c|c|}
\hline Peritoneal & \multicolumn{2}{|c|}{} & \multicolumn{2}{|c|}{ Pleural } \\
\hline $\begin{array}{l}\text { Nature } \\
\text { effusion }\end{array}$ & \multicolumn{2}{|c|}{ AgNOR size } & \multirow{2}{*}{ No } & \multicolumn{2}{|c|}{ AgNOR Size } & No \\
\cline { 2 - 6 } \cline { 5 - 6 } & $\begin{array}{c}0 \\
\text { to } 1+\end{array}$ & $\begin{array}{c}2+ \\
\text { to 3+ }\end{array}$ & & $\begin{array}{c}0 \\
\text { to } 1+\end{array}$ & $\begin{array}{c}2+ \\
\text { to 3+ }\end{array}$ & \\
\hline Reactive & 38 & 0 & 38 & 31 & 0 & 31 \\
\hline Malignant & 0 & 10 & 10 & 0 & 1 & 1 \\
\hline Total & 38 & 10 & 48 & 31 & 1 & 32 \\
\hline p value & \multicolumn{3}{|c|}{$<0.001$} & & \multicolumn{3}{|c}{$<0.001$} \\
\hline
\end{tabular}

\section{AgNOR Dispersion in Reactive and Malignant Peritoneal and Pleural Effusions}

AgNORs were less dispersed in reactive effusions than in malignant effusion. In reactive effusions AgNORs were limited to nucleoli (0) or with occasional dispersion outside the nucleoli (1+), whereas in malignant effusions AgNORs had moderate dispersion outside the nucleoli $(2+)$ or were widely dispersed throughout the nucleus $(3+)$.
Table-3 AgNOR Dispersion in Reactive and Malignant Peritoneal and Pleural Effusions

\begin{tabular}{|c|c|c|c|c|c|c|}
\hline \multicolumn{4}{|c|}{ Peritoneal } & \multicolumn{3}{|c|}{ Pleural } \\
\hline \multirow{2}{*}{$\begin{array}{l}\text { Nature } \\
\text { of effusion }\end{array}$} & \multicolumn{2}{|c|}{ AgNOR dispersion } & \multirow[t]{2}{*}{ No } & \multicolumn{2}{|c|}{ AgNOR dispersion } & \multirow[t]{2}{*}{ No } \\
\hline & 0 to $1+$ & $\begin{array}{c}2+\text { to } \\
3+\end{array}$ & & $\begin{array}{c}0 \text { to } \\
1+\end{array}$ & $\begin{array}{c}2+\text { to3 } \\
+\end{array}$ & \\
\hline Reactive & 38 & 0 & 38 & 31 & 0 & 31 \\
\hline Malignant & 0 & 10 & 10 & 0 & 1 & 1 \\
\hline Total & 38 & 10 & 48 & 31 & 1 & 32 \\
\hline$p$ value & $<0.001$ & & & $<0.00$ & & \\
\hline
\end{tabular}

Comparison of AgNOR Count in Reactive and Malignant Effusions

The mean AgNOR value in reactive effusion was $1.41 \pm 0.4$ and in malignant effusion was $2.23 \pm 1.6$ and standard error of mean was 0.07 and 0.22 respectively ( $\mathrm{p}$ value $<0.001$ ).

Table-4- The mean AgNOR value in effusions

\begin{tabular}{|c|c|c|c|}
\hline \multirow{2}{*}{$\begin{array}{l}\text { Nature } \\
\text { effusion }\end{array}$} & \multicolumn{2}{|c|}{ AgNOR count } & \multirow{2}{*}{$\begin{array}{l}\text { Standard Error } \\
\text { of Mean }\end{array}$} \\
\hline & Range & Mean & \\
\hline Reactive & $0.9-2.93$ & 1.14 & 0.07 \\
\hline Malignant & $3.21-6.82$ & 2.23 & 0.22 \\
\hline
\end{tabular}

Range of AgNOR Value in Reactive and Malignant Effusions

The range of AgNOR count in reactive effusions was 0.9 to 2.93. In malignant effusions the range of AgNOR count was 3.21 to 6.82 .

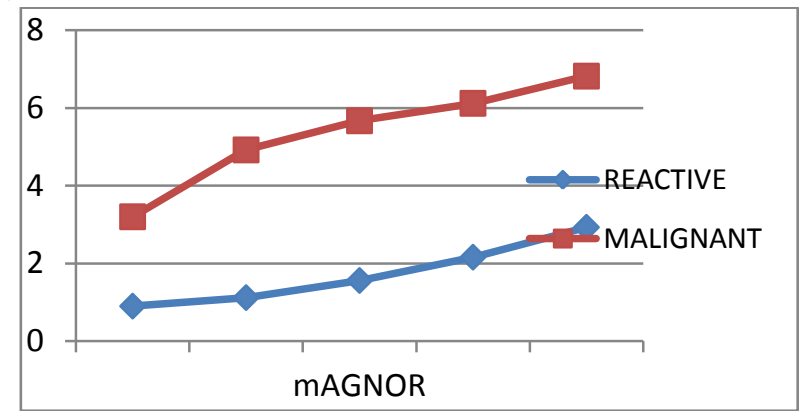

Figure -1: Range of AgORs count in reactive \& malignant effusions

The sensitivity and specificity of the test at mean AgNOR value of 1.04 was 94 and 13 respectively. As the mean AgNOR value increased the sensitivity decreased and specificity increased. The positive predictive value was also increasing with the increase in mean AgNOR values. 
Table-5: Sensitivity and specificity of mean AgNOR

\begin{tabular}{|l|c|c|c|c|}
\hline $\begin{array}{l}\text { Mean } \\
\text { AgNOR }\end{array}$ & $\begin{array}{c}\text { Sensitivi } \\
\text { ty }\end{array}$ & $\begin{array}{c}\text { Specifici } \\
\text { ty }\end{array}$ & $\begin{array}{c}\text { Positive } \\
\text { Predictive } \\
\text { Value }\end{array}$ & $\begin{array}{c}\text { Negative } \\
\text { Predictive } \\
\text { Value }\end{array}$ \\
\hline 1.04 & 94 & 13 & 62 & 84 \\
\hline 1.26 & 62 & 58 & 71 & 46.6 \\
\hline 1.52 & 44 & 67.7 & 70 & 41.6 \\
\hline 1.77 & 42 & 74 & 72.2 & 42.2 \\
\hline 2.03 & 38 & 90.3 & 85.7 & 45.9 \\
\hline 2.24 & 34 & 97 & 95.45 & 46.7 \\
\hline 2.57 & 24 & 100 & 100 & 43.5 \\
\hline
\end{tabular}

\section{ROC Curve}

Receiver Operating Characteristic curve which is a graph of true positive rate against false positive rate was plotted.

A test is considered diagnostically useful when the area under the ROC Curve is more than 0.5. In the present study area under the curve was found to be 0.68 .

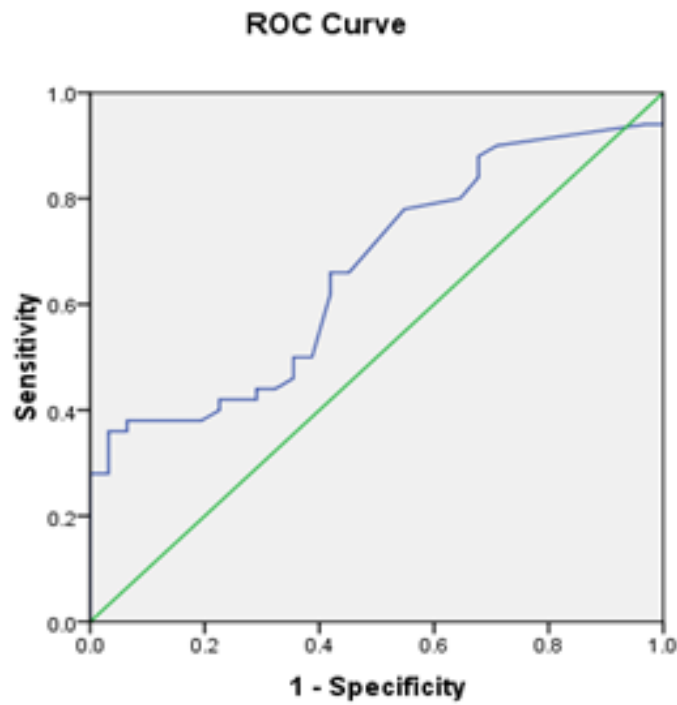

Fig. 2: ROC Curve showing sensitivity and specificity

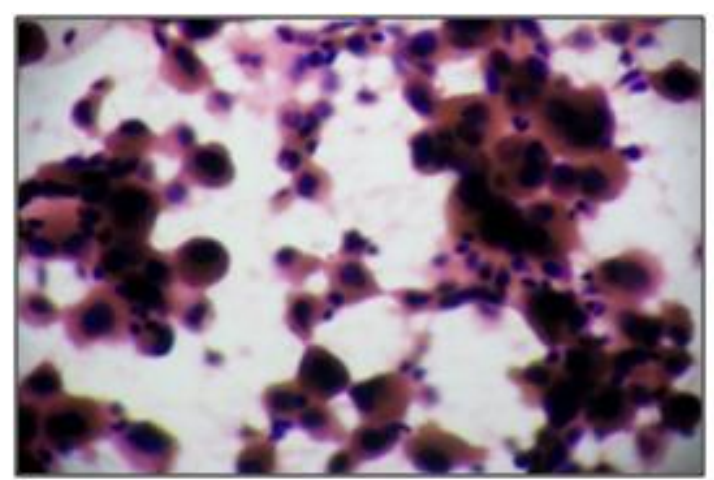

Fig.3: Pap smear of reactive mesothelial cell (40x)

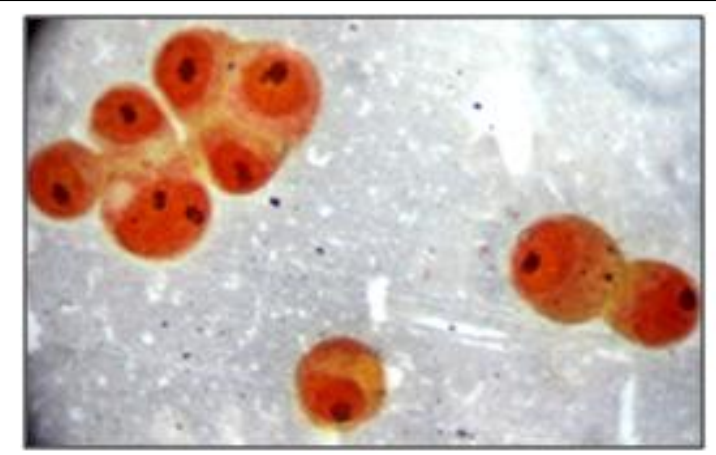

Fig.4: NORs in reactive effusion seen as 1-2 black dots of almost uniform size (40x)

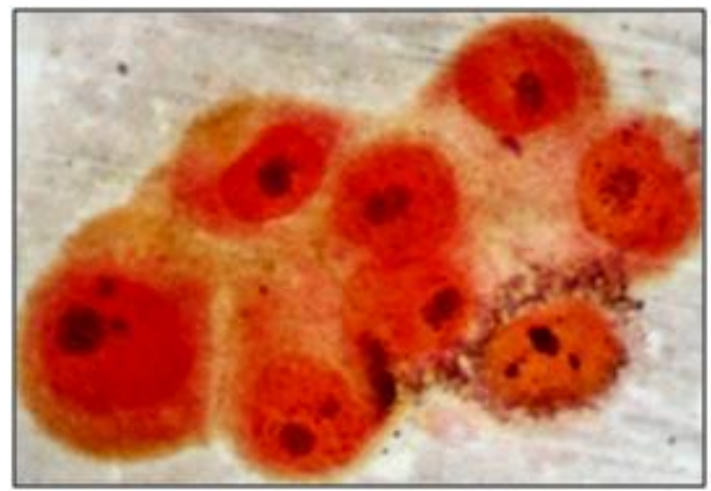

Fig.5: NORs in reactive effusion with uniform size (grade-0) and regular distribution (100x)

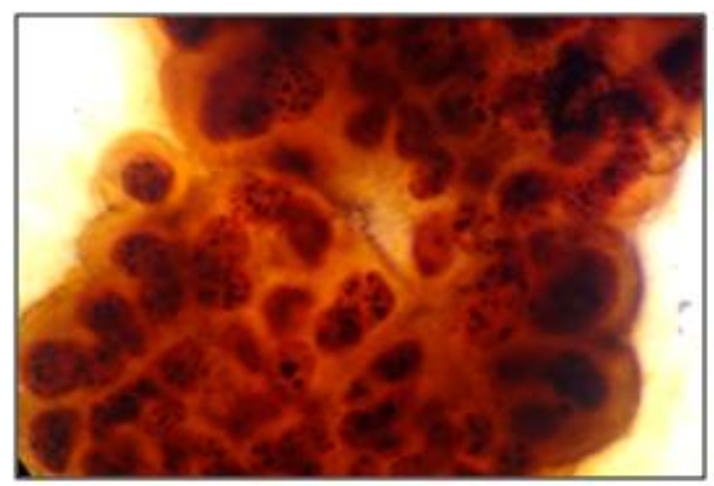

Fig.6: Heterogenously sized and irregularly distributed NORs in a malignant effusion (100x)

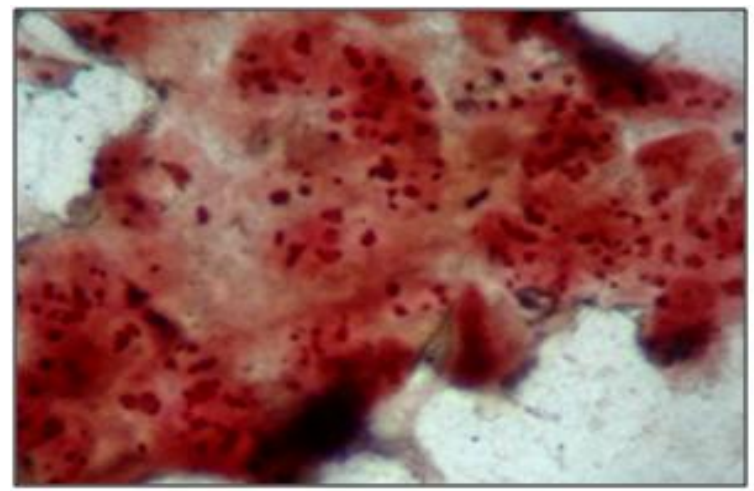

Fig.7: AgNOR staining done in a malignant effusion after destaining (40x) 


\section{Discussion}

80 effusions for which histopathological material were available for comparison were included for AgNOR staining

Age of the patients ranged from 21-88 years with frequent age group being 41-60 years (50\%). The mean age was 60.32 which was found to be higher as compared with most of the previous studies. There was a very strong female preponderance $(81.25 \%)$ similar to the study conducted by Mohamed Fagere ${ }^{[13]}$. Peritoneal effusions (60\%) outnumbered pleural effusions (40\%).

Only $14 \%$ of serous effusions were positive for malignant cells with remainder being reactive in nature. Malignant effusions were more common in females and in those above 50 years of age, in line with study by Torabi-Nezhad et al ${ }^{[11]}$.

The underlying cause for most of $(55 \%)$ reactive effusions was observed to be malignancy. Studies by Pretorius et al ${ }^{[15]} \&$ Burke et al ${ }^{[16]}$ also found that not all patients with metastases to the peritoneum were positive for malignant cells in effusions with false negative results ranging from $23 \%$ to $52 \%$. Non-malignant causes for reactive effusions in this study included tuberculosis, benign cystadenoma of ovary, various autoimmune diseases, leiomyoma and adenomyosis.

Peritoneal effusions were more likely to be malignant $(91 \%)$ than pleural effusions in concordance with the study by Mohamed Fagere ${ }^{[13]}$. In $81 \%$ of cases, the primary site of malignancy was the ovary, followed by lung $(9.5 \%)$ and stomach $(9.5 \%)$; as similar to studies by Karki S et al ${ }^{[5]}$.

In reactive effusions, AgNORs were more homogenous in size and graded as 0 and $1+$, while in malignant effusions AgNORs were heterogenous with grades of $2+$ and $3+$ as in many of the previous studies by Akhtar Khan et al ${ }^{[17]}$ and Gill et al ${ }^{[18]}$

The AgNOR black dots were more irregularly distributed in malignant effusions compared to reactive or normal mesothelial cells. Ibnerasa et al [12] also reported a highly significant difference $(p<0.001)$ in distribution of AgNORs between benign and malignant effusions. The range of AgNOR count in reactive effusions was 0.9 to 2.93 and for malignant effusions $3.21-6.82$ in the present study, comparable with that of Gill et al ${ }^{[18]}$ and Torabi-Nezhad et al (3.6 to 6.5) ${ }^{[11]}$.

The mean AgNOR count in reactive effusion was 1.4 similar to Trevisan et al ${ }^{[19]}$. For malignant effusion the mean was 4.29 for peritoneal and 4.98 for pleural effusion. This value was lower than that obtained in the study by Rocher et $\mathrm{al}^{[20]}$. The probable reason would be the less number of malignant effusions in the present study as compared to the previous one. Comparison of the mean AgNOR counts in reactive and malignant effusions showed statistically significant difference $(\mathrm{p}<0.001)$. This was in accordance with the study by Akhtar Khan et al ${ }^{[17]}$.

For all malignant effusions, high AgNOR counts was observed compared with benign effusions. The lowest mean AgNOR count in malignant group (3.21) was higher than the highest mean count observed in benign reactive effusions (2.93). Hence, the chance of false positivity is low. $95 \%$ confidence intervals for malignant and benign effusions ranged from 2.5 to 7.5 and 0.8 to 2.2 respectively and there was no overlap in the confidence intervals. This finding was comparable with that of Akhtar Khan et al ${ }^{[17]}$.

The sensitivity of this study was found to be decreasing with the increase in mean AgNOR count, but specificity and positive predictive value increased with the mean AgNOR count and at a value of 2.57 both these values were around $100 \%$. Above the value of 2.57 the underlying cause for effusion was mainly malignancy. In the present study, area under the Receiver Operating Characteristic curve was found to be 0.68 and hence AgNOR staining could be considered as diagnostically useful test.

Although AgNOR staining showed high specificity and positive predictive value for detection of malignancy, compared with cytological evaluation, the detection rate remained the same in the present study. Hence, considering the extra time required and the cost of reagents for AgNOR staining, this test should be used only when the cytodiagnosis is difficult and not routinely. 


\section{Conclusion}

$>$ Age of the patients with serous effusions ranged from 21-88 years with a mean age of 60.32.

$>65$ patients are females and 15 are males

$>$ Peritoneal cavity is the most common site for accumulated effusion.

Most effusions are reactive and females with ovarian cancer represents the majority among the patients with malignant effusion.

$>$ The AgNORs in malignant cells are greater in number, irregularly distributed throughout the nucleus and heterogeneous in size.

$>$ Benign cells are characterized by a lesser number of small, homogenously sized, regularly clustered AgNORs.

$>$ The range of AgNOR count in reactive effusions and malignant effusions varies from 0.9 to 2.93 and 3.21 to 6.82 respectively. The mean AgNOR count in reactive effusion is 1.4. For malignant effusion the mean AgNOR count is 4.29 for peritoneal and 4.98 for pleural effusion.

$>$ The lowest mean AgNOR count in malignant group (3.21) is higher than the highest mean count observed in benign reactive effusions (2.93). Therefore, the chance of false positivity is low.

$>$ As the mean AgNOR count increases the specificity and positive predictive value increases.

The area under the Receiver Operating Characteristic curve is found to be 0.68 and hence AgNOR Study can be used as a diagnostic test.

$>$ AgNOR study appears to be clinically useful as an additional diagnostic tool in serous effusion when the cytologic diagnosis is difficult.

> AgNOR study can be done on stained smears after distaining, so can be used even when extra unstained smear are not available

\section{References}

1. Egan M, Crocker J. Nucleolar organiser regions in pathology. Br J Cancer. 1992;65 (1):17.

2. Sujathan K, Kannan S, Pillai KR, Chandralekha B, Amma NS, Nair MK. Significance of AgNOR count in differentiating malignant cells from reactive mesothelial cells in serous effusions. Acta Cytol. 1996;40 (4):724-728.

3. Sandhya Panjeta Gulia,Emani Sitaramam, Karri Prasada Reddy. Role of Silver Staining Nucleolar Organiser Regions (AgNORs) in Lesions of the Oral Cavity. Journal of Clinical and Diagnostic Research. 2011;5(5): 1011-1015

4. Takahashi M.Effusions in body cavities. Color atlas of cancer cytology. Tokyo: Igaku-Shoin; 2000.

5. Karki S, Jha A, Sayami G. The Role of Argyrophilic Nucleolar Organizer Region (AgNOR) Study in Cytological Evaluation of Fluids, Especially for Detection of Malignancy. Kathmandu University Medical Journal. 2012; 10(1):44-47.

6. Mezger J, Stotzer O, Schilli G, Bauer S, Wilmanns W. Identification of carcinoma cells in ascitic and pleural fluid. Comparison of four panepithelial antigens with carcinoembryonic antigen. Acta Cytol. 1992; 36 (1):75-81.

7. Goodpasture C,Bloom S. Visualization of nucleolar organizer regions in mammalian chromosomes using silver staining. Chromosoma. 1975;53 (1):37-50.

8. Crocker J,Nar P. Nucleolar organizer regions in lymphomas. J Pathol. 1987; 151 (2):111-118.

9. Derenzini M, Nardi F, Farabegoli F. Distribution of silver-stained interphase NORs as a parameter to distinguish neoplastic from non-neoplastic reactive cells in human effusions. Acta Cytologica 1984; 339 (4): 491-498. 
10. Wolanski K, Whitaker D, Shilkin K, Henderson D. The use of epithelial membrane antigen and silver-stained nucleolar organizer regions testing in the differential diagnosis of mesothelioma from benign reactive mesothelioses. Cancer. 1998; 82 (3):583-590.

11. Torabi-Nezhad, A. Azarian. Differentiation between benign,reactive and malignant cells in serosal body fluids by AgNOR staining. Medical Journal of the Islamic Republic of Iran. 2002; 16 (2):95-100

12. Shazia N Ibnerasa, Naseer Ahmed Chaudhry,Saeed Akthar Khan. AgNOR Proliferative Index in Malignant Pleural and Peritoneal Effusions. International Journal of Pathology; 2005; 3(2): 86-90.

13. Muaz Osman Mohamed Fagere.Diagnostic Utility of AgNORs Staining of Serous Effusion among Sudanese Patients.International Journal of Science and Technology. 2016; 5(1): 36-42

14. Ahsan S, Tayyab M, Chaudhry NA, Khan SA. Silver staining nucleolar organizer region (AgNOR) typing in nodular hyperplasia of the prostate.Pak Postgraduate Med J 1992; 2(3): 67-72.

15. Pretorius RG, Lee KR, Papillo J, Baker S, Belinson J. False-negative peritoneal cytology in metastatic ovarian carcinoma. Obstet Gynecol. 1986; 68 (5):619-623.

16. Burke EC, Karpeh MS, Conlon KC, Brennan MF. Peritoneal lavage cytology in gastric cancer: an independent predictor of outcome. Ann Surg Oncol. 1998; 5(5):411415

17. Khan SA, Chaudhry NA, Khalid AW, Akhtar GN, Ibne-rasa SN. Patterns of argyrophilic nucleolar organiser regions in pleural and peritoneal effusions. J Coll Physicians Surg Pak. 2006; 16 (6):412-415.

18. Gill M, Singh U, Mahapatra QS, Gehlot S, Gupta V, Sen R. Role of argyrophilic nucleolar organizer region staining in identification of malignant cells in effusion. J Cytol. 2011; 28 (4):191-195.

19. Trevisan MS, Souza MI, Magna LA. Nucleolar organizer regions of mesothelial and carcinomatous cells in effusions. Diagn Cytopathol 1993; 9: 492-497.

20. Rocher AE, Blanco AM, Palaoro LA. Usefulness of AgNOR technique in the interpretation of serous effusions. Rev Med Chil 2000; 28: 963-968. 